Bol. Acad. peru. leng. 63. 2018 (233-242)

\title{
EL POETA Y SU ROL COMO EXÉGETA (DE SÍ MISMO) EN QUÍMICA DEL ESPÍRITU (1923), DE ALBERTO HIDALGO
}

\author{
Américo Mudarra Montoya
}

Universidad Nacional Mayor de San Marcos

Fecha de recepción: $\quad$ 13/03/2018

Fecha de aceptación: $\quad 31 / 05 / 2018$

Conocido es el acentuado personalismo presente en la poesía que produjo Alberto Hidalgo (1897-1967). Fue, no cabe duda, uno de sus rasgos más representativos tanto durante el tiempo que estuvo aquí, en su natal Arequipa, como en el que le tocó en tierras extranjeras, ya fuese en Buenos Aires o en Madrid. Si bien es cierto que este tono puede opacar por momentos a algunos de los brillos alcanzados en su copiosa obra, no habría razón por la cual eludir dicho rasgo en el trabajo de identificar las motivaciones y expectativas tras su escritura, tras su proyecto creador. De allí que tomarla, incluso, como eje desde el cual comenzar a releer su poesía, permitirá descubrir un nuevo ángulo en la figura de uno de los poetas más controversiales, más peculiares, más arriesgados, pero también uno de los 
más ignorados de la literatura peruana. En ese sentido, nuestro trabajo procura continuar con la indagación en torno a la poesía de Hidalgo ya iniciada, en un trabajo previo, en 2012, acerca de Química del espíritu (1923).

En aquella ocasión, se lo incluyó en una lectura en paralelo con obras de Juan Luis Velázquez y Xavier Abril, El perfil de frente (1924) y Hollywood (1931), respectivamente, con el fin de desentrañar algunos de los procedimientos usados por tres autores para reconocer cómo asimilaron estos autores las innovaciones técnicas y temáticas de la vanguardia europea. En el caso de Hidalgo, era evidente el afán por constituir un diálogo con el pensamiento occidental, por medio de la configuración de un yo poético moderno. Es así que en su poesía se reitera el proceso de fundación del mundo a partir del yo mismo, característico de los orígenes de la modernidad. El mundo se genera a partir de una primera certeza, aquella que brinda el yo singular, real, verídico y, en el caso de Hidalgo, poético. Este mismo yo posee un carácter estructural definido en la composición de Química del espíritu. La organización del poemario, que fuera publicado en Buenos Aires, así lo evidencia con sus tres partes definidas, cada una con un nombre específico: "poemas propios» (doce poemas); "poemas de la vida múltiple» (catorce poemas), y "poemas suramericanos» (diez poemas). El orden de las partes nos permite formular la posibilidad de entender el poemario como un desplazamiento desde el yo hasta el espacio sudamericano, su geografía. No es que el yo poético desaparezca, por el contrario, este se mantiene y predomina en todo el conjunto; sino que su presencia se matiza y adquiere dimensiones singulares.

En esta ocasión, el acercamiento a ese yo se realizará cuando decida ejecutar, en el mismo libro, un rol como exégeta de su propia obra. En la historia de la literatura occidental abundan los casos en los que un poeta reflexiona o comenta, con la intención explícita de interpretarlo, algún poema suyo. Hay que diferenciar este registro del manifiesto o del ensayo, ya que la mirada, el foco de atención del poeta está fijado — puesto que surge de él- a un determinado texto. Se tiene que recordar que, además, este poeta es el autor real, mientras que la instancia presente en el poema solo es el yo lírico, el personaje que no necesariamente debe ser una mera extensión del autor real. 
En el manifiesto se pretende exponer un programa estético. Un ejemplo, por dar alguno anterior a las vanguardias, es el «Prólogo» que el inglés William Wordsworth escribió en 1800, para sus Baladas Líricas. En este caso específico, Wordsworth exigía que los poetas comenzaran a utilizar más el lenguaje cotidiano, para que de ese modo se acercara la poesía de nuevo al pueblo. En el ensayo, por su parte, se trata de exponer la poética del autor, según su estilo, de acuerdo al tema que le preocupe, y con los argumentos que tiene al alcance en su época. De hecho, ha sido el ensayo el ámbito textual donde normalmente los poetas comentaban su poesía, así como las situaciones derivadas de su práctica. En este caso, la cantidad de títulos es ingente y milenaria, porque hay textos que cumplieron la misma función antes de la invención del término. Solo por citar uno, la Epístola a los Pisones, de Horacio, también conocida como Ars Poetica, producida en el siglo II de nuestra era, en la Antigua Roma, es una obra en la que el propio autor reflexiona sobre su arte. Como se observa, en ambos ejemplos se considera al autor real como la fuente de las ideas. La particularidad de Hidalgo es que en su poema es su yo lírico el que impone al lector su interpretación. En verdad, desmonta ante este el mecanismo que empleó para la construcción de su poema. Es decir, se vuelve exégeta de sí mismo.

Sin embargo, por más que se crea que es un rol poco habitual, Hidalgo no se encuentra solo en su ejercicio. En el siglo XvI, exactamente en 1584, en el contexto de la Contrarreforma Católica. El místico Fray Luis de León, en España, tuvo que agregar a su Cántico espiritual, debido a la solicitud de una priora de Granada, una serie de comentarios en prosa para «solo dar alguna luz general» (1987: 49) a «estas canciones compuesto [sic] en amor de abundante inteligencia mística» (49), ya que, de lo contrario, «no se podrán declarar al justo» (49). El resultado es que antes y después de cada estrofa, el poeta incluye párrafos en los que interpreta sus propios textos.

En un título de la sección "poemas sudamericanos» se incluye una nota al final, en la que explica la composición del texto. El poema es 
«paisaje uno y trino», y en las primeras líneas de la nota se puede leer lo siguiente: «el título de esta composición me exime de exégesis. pero [sic] como los espíritus tardos están en mayoría, enciendo el faro de mis palabras para alumbrarles el camino» (2011 [1923]: 71). Es cierto que se podría argüir que una marca paratextual como esa, una nota al pie de página, es agregada por el autor real y no por el yo lírico. No obstante, es el propio Gérard Genette, en su clásico Umbrales, quien apunta sobre estas marcas lo siguiente: "que no sabemos si debemos considerarlas o no como pertenecientes al texto, pero que en todo caso lo rodean y lo prolongan precisamente por presentarlo» (2001: 7). La certeza sobre los paratextos es que contribuyen en guiar, en orientar, la lectura del texto del cual dependen. Los recursos utilizados para ellos son diversos. La posibilidad de que pertenezca al texto conlleva que su fuente no sea el autor real, sino el yo lírico. Hay que contemplar que se tratan de dos dimensiones diferentes: la escritura y la realidad. Considerando el hecho de que el yo lírico de Química del espíritu es la instancia que organiza el libro entero, cabría pensar que esta nota le pertenece al yo lírico. Entendiendo esta categoría, según lo planteado por Samuel R. Levin, (1987). ¿Es, acaso, una estrategia para representar su configuración como un yo poético moderno? ¿Qué significados se albergan detrás de un gesto como este?

La recepción crítica de la poesía de Hidalgo en el Perú, de acuerdo con Brenda Camacho (2014) y ampliando lo expuesto por ella, ha atravesado por tres momentos definidos: la fundación de la crítica literaria peruana, el interés por las relaciones entre literatura y sociedad, y la revaloración de la vanguardia literaria. Como se evidenciará a continuación, durante todo el siglo $\mathrm{xx}$, Hidalgo fue un autor subestimado por la academia literaria peruana. Esta situación contrasta con lo que ocurrió en Argentina, lugar donde residió buena parte de su vida, ya que, en 1967 (meses antes de morir) obtuvo un importante premio de parte de la Sociedad Argentina de Escritores, en un concurso organizado por la Fundación de la Poesía Argentina. De allí que resulte necesario establecer un acercamiento, contemporáneo y sin mezquindades, a su obra poética. 
https://doi.org/10.46744/bapl.201801.010

La primera etapa se caracteriza por la publicación de dos libros primordiales para los estudios locales sobre poesía: Panorama actual de la poesía peruana (1938), de Estuardo Núñez, y La poesía postmodernista peruana (1954) de Luis Monguió. Ambos autores, cabría afirmar, determinaron el cariz de la inserción de Hidalgo al canon literario peruano. Para ellos, Hidalgo era uno de los fundadores de la vanguardia: el primero, aunque no el mejor. Será a través de la comparación con la poesía de César Vallejo que se desestimará estéticamente a la obra de Hidalgo. En ese sentido, su inserción al canon se dio en un plano secundario: como un autor importante para entender la historia de la poesía peruana, pero cuya obra no valía lo necesario, no despertaba la atención, como para emprender un análisis. La ausencia de valor propio radicalizó poco a poco su posición secundaria en el canon hasta convertirlo prácticamente en un autor prescindible, casi invisible, que no era necesario leer. Su presencia se redujo, durante muchos años, a ser una referencia más en cualquier manual de historia literaria. Se podía saber dónde había nacido y qué libros había publicado, pero no cuáles habían sido los probables sentidos de sus expectativas para con la poesía.

Es con la publicación de la Antología de la poesía peruana (1973), de Alberto Escobar, que se consolida la institución crítica peruana. Así también, aparece una serie de investigaciones, principalmente de carácter histórico, que procuran describir el panorama poético en relación al tema de la identidad peruana y la historia social del país. Aquí hay que nombrar a «Historia de la literatura del Perú Republicano» (1980) y La formación de la tradición literaria en el Perú (1989), de Antonio Cornejo Polar; a «Vanguardismo y revolución» (1984), de Washington Delgado, y al volumen colectivo Literatura y sociedad en el Perú II. Narración y poesía: un debate (1982). Esta crítica aprovecha cualquier oportunidad para establecer estos vínculos y elaborar una ontología del ser peruano. Este aumento de la producción académica ofrece las condiciones adecuadas para la recuperación de la obra poética de Hidalgo ( Alberto Hidalgo, hijo del arrebato» (1987) de Edgar O’hara) e, incluso, aparecen algunos artículos especializados dedicados íntegramente a la vanguardia poética ( «La poesía vanguardista en el Perú» (1982) de Mirko Lauer, artículo que será el germen de sus posteriores investigaciones). 
A partir del 2001, gracias a la antología de Mirko Lauer, Antología de la poesía vanguardista peruana, se inicia una revaloración de la vanguardia poética y una serie de análisis sobre los aspectos ideológicos en relación a los estéticos. El mismo Lauer recupera parte de la poesía de Alberto Hidalgo al incluirlo en su antología y al dedicarle una parte del ensayo que abre su selección («La poesía vanguardista peruana 1916-1930»). Lauer contribuirá posteriormente al estudio de la obra de Hidalgo por medio de su sugerente libro Musa mecánica. Maquinas y poesía en la vanguardia peruana (2003), en el que analiza las relaciones entre la poética futurista y la poesía de la primera vanguardia, la presencia de la máquina y la configuración de algunas de las poéticas vanguardistas. Siguiendo esta línea, Marco Thomas Bosshard propone la posibilidad de estudiar la poesía de Hidalgo a partir del enfoque de género («Virilidad y vanguardia. Construcciones de identidades masculinas y representaciones de lo femenino en Hidalgo, Abril, Adán, Varallanos y Churata» (2005)). Tal vez el más importante suceso editorial, respecto a la contribución crítica sobre la poesía del poeta peruano, sea la publicación de Alberto Hidalgo, el genio del desprecio: materiales para su estudio (2006), de Álvaro Sarco. Dicho texto reúne una serie de referencias fundamentales y, prácticamente, inhallables alguna de ellas para el estudio de la escritura de Hidalgo. También, en esta década se realiza una serie de reediciones de algunos libros de la vanguardia poética peruana. Muestra de ello son 9 libros vanguardistas (2001), de Mirko Lauer, en el que se incluye Química del espíritu, y Poesía vanguardista peruana (2009) de Luis Fernando Chueca, en el que se reedita Descripción del cielo. La nómina termina con la antología, a cargo del español Juan Bonilla, Poemas simplistas (2011), quien a partir de su investigación sobre Filippo Tommaso Marinetti y la difusión del futurismo en Europa termina por acceder a la obra de Hidalgo. Sin duda, en la última década, debido a la revaloración de la vanguardia poética se ha escrito mucho más sobre la obra de Hidalgo que en la segunda mitad del siglo xx.

Si bien Brenda Camacho se fija en algunos aspectos de Química del espíritu, consideramos pertinente concentrarnos en Bonilla, puesto que en su lectura le presta mayor atención al prólogo que para este libro debió 
preparar el escritor español Ramón Gómez de la Serna, conocido —en esos años- por contribuir en difundir las obras de diversos poetas jóvenes vanguardistas. Al hacerlo, al leer a dicho prólogo, Bonilla incide en un punto que también observaremos en Hidalgo: la performance del poeta en su rol como exégeta. Al respecto, Bonilla apunta: «Gómez de la Serna había retratado ya a Hidalgo en las páginas de Pombo, declarándolo una de las voces más impactantes de América. El prólogo a química del espíritu [sic] es un texto débil, un compromiso que Ramón se quitó de encima rápidamente, más entusiasta con el entusiasmo del poeta que con sus poemas» (2011: 15).

De acuerdo con la interpretación de Bonilla, la cual lo lleva a realizar esa afirmación, las definiciones que propone Gómez de la Serna acerca de la poesía de Hidalgo, además de restringirse a la actitud del poeta peruano, son —a su vez- definiciones «de los propósitos esenciales del propio mundo ramoniano: hacer del mundo una red de cosas unidas en su literatura de manera diferente a cómo se unen en la realidad, por pasillos secretos construidos con metáforas o juegos de palabras. Ramón es faro evidente más del segundo libro que del primero, pero también en química del espíritu [sic] es perceptible su influencia» (15). En pocas palabras, para Bonilla, Gómez de la Serna disimula, en su comentario a la poesía de Hidalgo, una apreciación de su propia escritura. Por esta razón, y porque tampoco alude a versos concretos del libro, es que Bonilla considera que Gómez de la Serna no ofrecería ninguna genuina lectura.

Las «definiciones», como las denomina Bonilla, que Gómez de la Serna propone de Hidalgo son dos expresiones que, sin duda, harían pensar en algunas de sus célebres greguerías. La primera es expresada así: «Esa mecánica del saltamontismo imaginativo y efectivo de Hidalgo - anterior en su invención a los que vuelan sin motor o a la velaexplica la rareza de este libro, su encanto impensado, imprevisto, impar» (2001 [1923]: 15). Agrega, con intención de explicarse, líneas después: «Él salta, tiene la alegría de los mayores saltos — nada de largos vuelospero cuando se hospeda en la nueva imagen, en cuanto descansa un poco en la nueva imagen distante y única, surge su tragedia humana, y la plañe y la recoge de veras, en un estilo nuevo y cada vez profundo» 
(16). Como se puede ver, aunque someramente, Gómez de la Serna sí se refiere a la escritura de Hidalgo. La otra definición es más puntual: «verdadero agrimensor del horizonte» (16). En la primera definición («el saltamontismo imaginativo y efectivo»), sin necesidad de aterrizar, el poeta se traslada de un punto a otro del planeta. En la segunda definición («verdadero agrimensor del horizonte»), el poeta es alguien que mide y delimita algo tan inconmensurable como el horizonte. En ambos casos, la figura de Hidalgo que se plantea es la de un creador con la capacidad de superar los obstáculos de la realidad, lo que —en los términos tratadossignificaría que la lógica y la razón no impiden su expresión en la escritura. Resulta evidente que Bonilla no consideró que un poeta, aunque se valga de sus propios recursos estilísticos, también puede reflexionar sobre la poesía de alguien más.

El poema "paisaje uno y trino», a decir del yo lírico en su nota al mismo texto, «se trata de tres POEMAS ENCHUFADOS» (2011 [1923]: 71). He aquí el poema:

el corazón de la noche

POR LOS CIELOS DEL BOHIO

andando al compás del mío

IBA LA LUNA EN SU COCHE

sin hacerle ni un reproche

DE AMOR LA BESABA EL RÍO

tenía miedo del frío

EN UN INMENSO DERROCHE

a mí la noche me amaba

YO LA QUERÍA A LA LUNA

que el amor es cosa bruna

LO PRUEBA EL QUE ME ENGAÑABA (71)

La explicación, desde la perspectiva del yo lírico, resulta necesaria, pues el mismo subestima a la gran mayoría de sus lectores, como ya se mencionó líneas más arriba. Es así que escribe: «ocurre que al mirar un paisaje vemos varios paisajes superpuestos, cuya descripción parece 
imposible hacer en un solo poema, puesto que es uno solo el paisaje» (71). Aquí vemos que las definiciones ofrecidas por Gómez de la Serna se ajustan a las características del personaje protagonista del poema. Este se traslada en más de un plano, entre la superficie terrestre, con sus progresivas estribaciones, y el cielo, alto con los astros inalcanzables. Pero, también, es el poeta que se comporta como el agrimensor que Gómez de la Serna había dicho que era un «verdadero agrimensor del horizonte». De allí que en su intento de trasladar, de rescatar algunas de las propiedades del mundo real — del paisaje que contempla— en la página de papel, el poeta decida producir un mapa con sus versos, disponiéndolos como si fuesen los trazos necesarios, de modo que los lectores sean capaces de ver, de imaginar, cabría decir, aquel paisaje instantáneo. Es lo que describe como «la sensación total de la visión» (71).

Este «método», como es nombrado en la nota por el yo lírico, es una tentativa de transgredir los límites de la escritura. Desde su posición, se trata de un «descubrimiento» que le pertenece. Y, he aquí el personalismo de Hidalgo que trasluce en su yo lírico. Las siguientes líneas lo revelan claramente: «calguien lo ha hecho antes que yo? que lo declare, para gritarle: hermano mío!» (71). Pero más allá de esta felicitación que a sí mismo se hace, lo que habría que observar es el rol que adopta el yo lírico. Ha encontrado un recurso gráfico para traducir una experiencia sensorial específica. Por unos instantes, se deja al descubierto ante los lectores el proceso que siguió para lograr tal efecto. Estamos ante un poema que es su resultado, pero que también incluye - exhibe- parte de su elaboración.

Un poema que es tres porque, para finalizar la nota, se indica: «he aquí la luz; primer poema: todos los versos; segundo poema: los versos escritos en minúsculas exclusivamente; tercer poema: los versos escritos en mayúsculas exclusivamente» (71). La alternancia de las grafías también influye en la creación del efecto previsto por el yo lírico. Ya no es solo la posición de los versos. Tampoco es únicamente las imágenes a las que se hace referencia. Sin duda, en este poema, aparentemente tan sencillo, el iluminado fue el propio poeta. 
https://doi.org/10.46744/bapl.201801.010

\section{BIBLIOGRAFÍA}

BONILlA, J. (ed.) (2011) Alberto Hidalgo. Poemas simplistas. Lima: Revuelta.

CAMACHO, B. L. (2014). Los orígenes de la vanguardia. Una lectura de Química del espíritu y Descripción del cielo de Alberto Hidalgo. Tesis para obtener el grado académico de doctor en Literatura Peruana y Latinoamericana. Lima: Facultad de Letras y Ciencias Humanas. Unidad de Posgrado.

FRAY LUIS DE LEÓN (1987). Poesía sacra. Lima: Orbis.

HIDALGO, A. (2001 [1923]). Química del espíritu. En: Mirko LAUER (ed), 9 libros vanguardistas. Lima: El Virrey.

MAYORAL, J. A. (comp.) (1987). Pragmática de la comunicación literaria. Madrid: Arco Libros.

MUDARRA, A. (2012) «¿Búsqueda de lo real o afán de ruptura? Procedimientos de la vanguardia poética peruana (Hidalgo, Velázquez y Abril)». En: Gladys FLORES HEREDIA, Javier MORALES MENA y Marco MARTOS (eds.) Actas del Congreso Internacional de "Poesía Hispanoamericana: de la Vanguardia a la Posmodernidad». Lima: Academia Peruana de la Lengua, Facultad de Letras y Ciencias Humanas de la Universidad Nacional Mayor de San Marcos y San Marcos, pp. 47-60. 